\title{
Preface to the third edition
}

It gives me great pleasure to present this third edition of my book, Socialismo, cálculo económico y función empresarial, to Spanish-speaking readers and students. Four years ago, I made several observations in the preface to the second edition, and today these continue to apply and thus should be taken into account.

Also, in the interim between editions, two important milestones have passed. First, the English version of the book, entitled Socialism, Economic Calculation and Entrepreneurship, has been completed, and soon it will be published in England and the United States. Second, an ever-increasing number of researchers, students and professors, in both Spain and the rest of the world, have begun to show an interest in delving into the dynamic conception of competition and market processes, and in applying it to the theory of the impossibility of socialism and economic interventionism. This growing interest has necessitated the establishment of a scientific journal which, under the title, Market Processes: European Journal of Political Economy, ${ }^{*}$ draws together and provides a medium for the publication of research, especially that of the new generations of scholars who form part of what is today viewed on an international scale as the booming and highly productive Austrian school of economics. These scholars are developing a paradigm capable of replacing the one which has prevailed thus far, and which has already entered into a phase of severe crisis, decline and disintegration.

I must acknowledge the great enthusiasm and university spirit shown, year after year, by the students who use this work as a textbook in my undergraduate classes. Together with my doctoral students and assistants as Chair of Political Economy, which I teach at the Universidad Rey Juan Carlos in Madrid, they provide the greatest incentive and support for me to continue advancing in Spain the research program of the Austrian school of economics. Finally, I dedicate this book to Israel M. Kirzner.

Jesús Huerta de Soto

Formentor, August 22, 2005

* Procesos de Mercado: Revista Europea de Economía Política. Interested readers can request the different published numbers of the journal at ommcamp@teleline.es; see also www.jesushuertadesoto.com. 
Jesús Huerta de Soto - 9781849805001 Downloaded from PubFactory at 04/26/2023 02:11:58AM via free access 